\title{
On the Mn-In-Ni Diatoms: Electronic Properties Depending on Spin Multiplicity
}

\author{
Aslı Öztürk Kiraz ${ }^{1, *}$, Halit Kan ${ }^{1}$, Nuri Kolsuz ${ }^{1}$ and Şakir Erkoç ${ }^{2}$ \\ ${ }^{1}$ Department of Physics, Pamukkale University, Denizli, Turkey \\ ${ }^{2}$ Department of Physics, Middle East Technical University, Ankara, Turkey \\ Corresponding Author: Aslı Öztürk Kiraz
}

\begin{abstract}
In this study, $\mathrm{Ni}, \mathrm{Mn}$ and In atoms formed by different combinations of diatoms due to the spin multiplicity of electronic structure characteristics have been investigated. Calculations have been performed by Density Functional Theory within B3LYP functional and CEP-121G basis set. Diatoms with the first five spin multiplicity configurations have been investigated and the most stable state has been determined. The energetics, such as binding energy, frontier molecular orbital energies of six possible diatoms have been calculated in their ground state with their lowest five spin multiplicities.
\end{abstract}

Keywords: Mn-In-Ni diatoms, density functional theory, electronic properties, spin multiplicity.

\section{INTRODUCTION}

Clusters are defined as atom groups formed by a few or millions of atoms. Some researchers approved the clusters as the fifth state of the matter since the general definition is of clusters are the finite structures combined from different disciplines [1]. For this reason, there has been a considerable amount of interest in the theoretical and experimental studies of the atomic clusters in recent years because of their electronic and magnetic properties and practical applications in many different fields. Scientist run across many difficulties in the calculation of thermodynamical properties because, when the cluster size decrease, the quantities like temperature, surface tension, surface area, volume are not clearly explained for the macroscopic system [2-3]. Even for very small size clusters ab initio calculations are still difficult so parametrised models are more probable in this regard [4]. In small cluster simulations one of the most incompleteness is the inaccessibility of realistic potential functions explaining the interactions between the atoms in the cluster and also results of the simulations are related to the functional form of the potential. The results derived from the simple pair potentials are not satisfy quantative informations for the conceptualisation of the microcluster structures, but three-body interactions used in the simulations are gained considerable results [5-6].

In the recent years, there is an increasing interest to understand the metalic structure properties in the border of nano scale because of the minimization of the electronic devices. Metal clusters are begining with the diatomic molecule access to several thousand atoms with a countable number of atoms [7]. In literature, there are different types of studies related the materials including $\mathrm{Mn}, \mathrm{Ni}$, In atoms [815]. Also there are alloys with various ratios of the $\mathrm{Mn}, \mathrm{Ni}$, In atoms and theoretical prediction of shape memory behavior [16-21]. In these studies structural, electronic and magnetic properties of the shape memory behaviour materials have been investigated. Small atomic clusters are known to display geometrical arrangements and electronic properties that are significantly different from their bulk properties [15]. There is no an encountered study with the heteroatomic microclusters containing $\mathrm{Mn}$, $\mathrm{Ni}$, In atoms. In the studies with the Mn clusters the magnetic properties of the clusters have been investigated [22-27]. Also, there are studies related with the $\mathrm{Mn}$ ions [28-30] and diatomic alloys like MnNi, MnIn NiIn in the literature [31-34].

This work reports the electronic properties and energetics of six different diatoms composed of from the atoms $\mathrm{In}, \mathrm{Ni}, \mathrm{Mn}$ have been investigated. The three homonuclear diatoms $\left(\mathrm{In}_{2}, \mathrm{Ni}_{2}, \mathrm{Mn}_{2}\right)$ and the three heteronuclear diatoms (NiMn, NiIn, MnIn) have been studied in their ground state and the lowest first five spin multiplicity states. In the literature in most of the electronic structure calculations usually the lowest spin multiplicity case is considered. There is no guarantee that the lowest multiplicity corresponds to the most stable state. It is essential to check higher spin states for the stability of atomic systems. Diatoms are the building blocks of the clusters and nanoparticles. Understanding diatoms 
will give considerable information for the larger systems.

\section{Method of Calculation}

The energetics, frontier orbital energies, dipol moments, dissociation energies of the $\mathrm{Mn}, \mathrm{Ni}$, In diatoms with the various spin multiplicities are calculated by density functional theory (DFT) [35] with B3LYP exchange-correlation functional [36] and core effective potential (CEP) [37, 38] basis functions with ECP triple-split basis (CEP-121G). All the calculations have been performed by using Gaussian 09.C1 [39] program and GaussView 5.0.8 [40] was used for visualization of the calculation results.

The core effective potentials or pseudopotential methods have been derived from numerical Dirac-Fock atomic wavefunctions using shape-consistent valance pseudo-orbitals and widely used for the systems with many electrons. Because these functions are including relativistic effects also which take into account only the valance electrons and the core electrons are excluded from the calculations. This is another advantage of CEP basis functions, which reduces computation time considerably.

In CEP-121G basis set, the valance electrons have three sets of atomic orbitals composed of 1,2 and 1 Gaussians, respectively. In quantum chemistry studies, CEP basis sets have been widely used to investigate the equilibrium structures and to calculate the spectroscopic properties of systems with heavy atoms $[37,38,41,66]$.

\section{RESULTS AND DISCUSSIONS}

The geometri optimization is the beginning point of the characteristics of the cluster properties so we optimized the equilibrium geometries of $\mathrm{Ni}_{2}, \mathrm{Mn}_{2}$, $\mathrm{In}_{2}, \mathrm{InNi}, \mathrm{NiMn}, \mathrm{MnIn}$. The binding energy $\left(\mathrm{E}_{\mathrm{b}}\right)$, the equilibrium interatomic seperations $\left(r_{e}\right)$, fundamental frequencies $\left(\omega_{\mathrm{e}}\right)$ and total energies $\left(\mathrm{E}_{\mathrm{T}}\right)$ depending on spin multiplicities corresponding to the ground state and the most stable spin states of both homonuclear and heteronuclear diatoms $\mathrm{Ni}_{2}, \mathrm{Mn}_{2}, \mathrm{In}_{2} \mathrm{InNi}, \mathrm{NiMn}$, MnIn have been investigated by performing DFT method calculations with B3LYP/CEP-121G basis set. Some of the calculated values are presented in Tables 1-9.

\section{Homonuclear diatoms}

$\mathrm{Ni}_{2}$ Diatom

For $\mathrm{Ni}_{2}$, the energy of the singlet, triplet, quintet, septet and nonet spin multiplicities are calculated and the triplet spin state is found to be as the most stable state. Fig. 1 shows the variation of the total energy versus the spin multiplicity for $\mathrm{Ni}_{2}$.

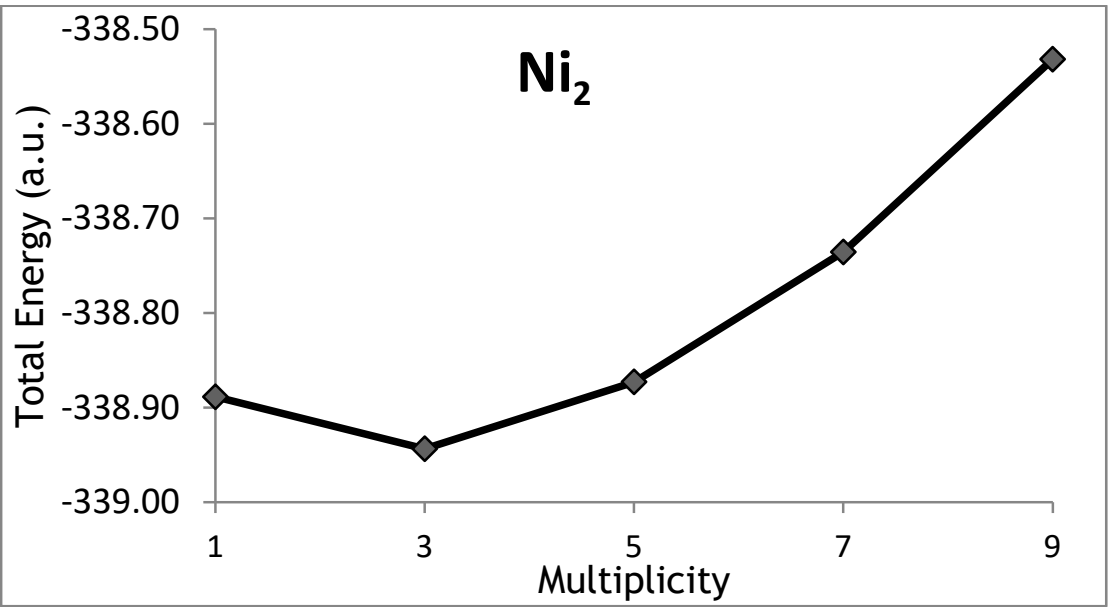

Figure1. The variation of the total energy versus the spin multiplicity for $\mathrm{Ni}_{2}$.

For the $\mathrm{Ni}_{2}$ homonuclear diatom the calculated quantities for the most stable structure and its ground state are given in Table 1 . In the present study, bond length and vibrational frequency of $\mathrm{Ni}_{2}$ diatom are calculated to be $2.0760 \AA, 347.92 \mathrm{~cm}^{-1}$ in the minimum multiplicity state (multiplicity $=1$ ) and $2.0710 \AA, 356.74 \mathrm{~cm}^{-1}$ in the most stable spin state (multiplicity $=3$ ) by B3LYP/CEP-121G level of theory. It is used singlet spin state of $\mathrm{Ni}$ atom which is the most stable state for the calculation of the binding energy for the ground state of $\mathrm{Ni}_{2}$. Conformably, for the calculation of the binding energy of $\mathrm{Ni}_{2}$ in the triplet state it is considered triplet state is the most stable state of $\mathrm{Ni}$ atom. The calculated ground state binding energy is higher than the experimental value but on the other hand lower in the triplet state. The differences in the calculations are arised from the calculation processes and the different spin states. 
Table 1. Spectroscopic constants of $\mathrm{Ni}_{2}$ in ground state (with minimum multiplicity) and in the most stable state (with minimum total energy). Equilibrium interatomic separation $r_{e}(\AA)$, fundamental frequency $\omega_{\mathrm{e}}\left(\mathrm{cm}^{-1}\right)$, total energy $\mathrm{E}_{\mathrm{T}}$ (a.u.).

\begin{tabular}{|c|c|c|c|c|c|}
\hline $\begin{array}{c}\text { Multiplicity } \\
(2 \mathrm{~S}+1)\end{array}$ & $\mathrm{r}_{\mathrm{e}}$ & $\omega_{\mathrm{e}}$ & $\mathrm{E}_{\mathrm{T}}$ & Method & Reference \\
\hline 1 & 2.0760 & 347.92 & -338.8888 & DFT & This work \\
\hline 3 & 2.0710 & 356.74 & -338.9437 & DFT & This work \\
\hline 3 & 2.13 & & & DFT & {$[42]$} \\
\hline & 2.06 & & & DFT & {$[43]$} \\
\hline & 2.01 & & & MD & {$[43]$} \\
\hline & 2.05 & & & DFT & {$[49]$} \\
\hline & 2.155 & & & Exp. & {$[43]$} \\
\hline & 2.05 & & & MD & {$[46]$} \\
\hline & 2.01 & & & MD & {$[47]$} \\
\hline & 1.99 & & & Ab initio & {$[47]$} \\
\hline & 2.20 & 289 & & CI & {$[48]$} \\
\hline & 2.60 & 236 & & HF & {$[48]$} \\
\hline & 2.38 & 240 & & RHF & {$[50]$} \\
\hline & 2.00 & & & DF & {$[51]$} \\
\hline & 2.04 & 344 & & ECP-GVB-CI & {$[52]$} \\
\hline & 2.18 & 320 & & DFT & {$[53]$} \\
\hline & 2.33 & 211 & & ECP-CI & {$[54]$} \\
\hline
\end{tabular}

\section{$\mathrm{Mn}_{2}$ Diatom}

For $\mathrm{Mn}_{2}$, the energy of the singlet, triplet, quintet, septet and nonet spin multiplicities are calculated and the nonet spin state is found to be as the most stable state as seen from Fig.2.

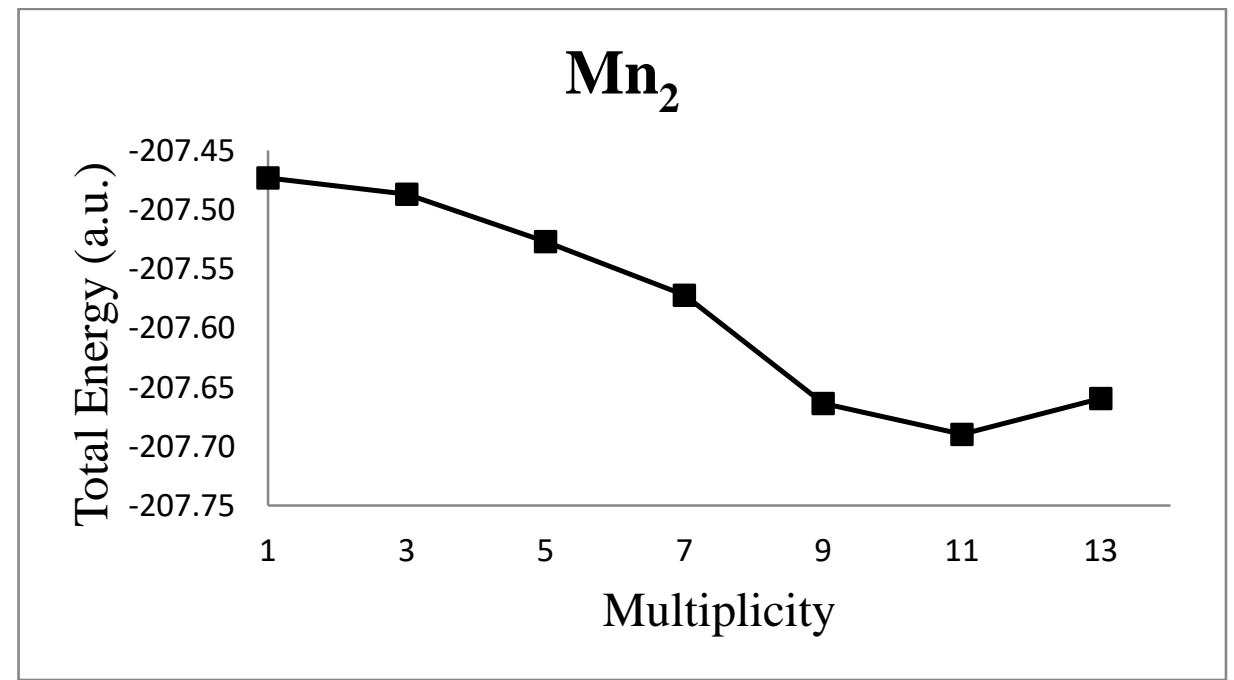

Figure 2. The variation of the total energy versus the spin multiplicity for $\mathrm{Mn}_{2}$.

$\mathrm{Mn}_{2}$ homo-nuclear diatom for the most and energetically most favorable ground state are given in Table 2. In the present study, bond length and vibrational frequency of $\mathrm{Mn}_{2}$ diatom are calculated to be, respectively, $1.6604 \AA, 719.49 \mathrm{~cm}^{-1}$ in the ground state and $2.5884 \AA, 214.06 \mathrm{~cm}^{-1}$ in the most stable spin state (multiplicity=11) by B3LYP/CEP-121G level of theory. The present results are not compatible with the literature. The diffrences in the calculations are arised from the calculation processes and the different spin states. It is used doublet spin state of Mn atom which is the most stable state while the calculation of the binding energy for the energetically most favorable ground state of $\mathrm{Mn}_{2}$. Conformably, for the calculation of the binding energy of $\mathrm{Mn}_{2}$ in the nonet state it is considered sextet state is the most stable state of Mn atom. 
Table 2. Spectroscopic constants of $\mathrm{Mn}_{2}$ in ground state [with minimum multiplicity] and in the most stable state (with minimum total energy). Equilibrium interatomic separation $r_{e}(\AA)$, fundamental frequency $\omega_{e}\left(\mathrm{~cm}^{-1}\right)$, total energy $\mathrm{E}_{\mathrm{T}}$ (a.u.).

\begin{tabular}{|c|c|c|c|c|c|}
\hline $\begin{array}{c}\text { Multiplicity } \\
(2 \mathrm{~S}+1)\end{array}$ & $\mathrm{r}_{\mathrm{e}}$ & $\omega_{\mathrm{e}}$ & $\mathrm{E}_{\mathrm{T}}$ & Method & Reference \\
\hline 1 & 1.6604 & 719.49 & -207.4869 & DFT & This work \\
\hline 11 & 2.62613 & 207.50 & -207.6897 & DFT & This work \\
\hline 1 & 1.651 & & & DFT & {$[57]$} \\
\hline 3 & 1.564 & & & DFT & {$[57]$} \\
\hline 5 & 1.753 & & & DFT & {$[57]$} \\
\hline 7 & 1.860 & & & DFT & {$[57]$} \\
\hline 9 & 2.094 & & & DFT & {$[57]$} \\
\hline 11 & 2.506 & & & DFT & {$[57]$} \\
\hline & 3.29 & 53.46 & & MCQDPT2 & {$[55]$} \\
\hline & 3.42 & 62.64 & & MCQDPT2 & {$[55]$} \\
\hline 11 & 2.53 & 240.47 & & NEVPT2 & {$[58]$} \\
\hline 11 & 2.501 & 245.8 & & Exp. & {$[59]$} \\
\hline 1 & 3.4 & 68.1 & & LSDA & {$[47]$} \\
\hline & 1.62 & & & BPW91 & {$[60]$} \\
\hline & 2.50 & & & BP86 & {$[56]$} \\
\hline & 3.562 & & & MCQDPT & {$[60]$} \\
\hline & 3.11 & 47.3 & & DFT & {$[61]$} \\
\hline
\end{tabular}

\section{$\mathrm{In}_{2}$ Diatom}

For $\mathrm{In}_{2}$, the energy of the singlet, triplet, quintet, septet and nonet spin multiplicities are calculated and the triplet spin state is found to be as the most stable state as seen from Fig.3.

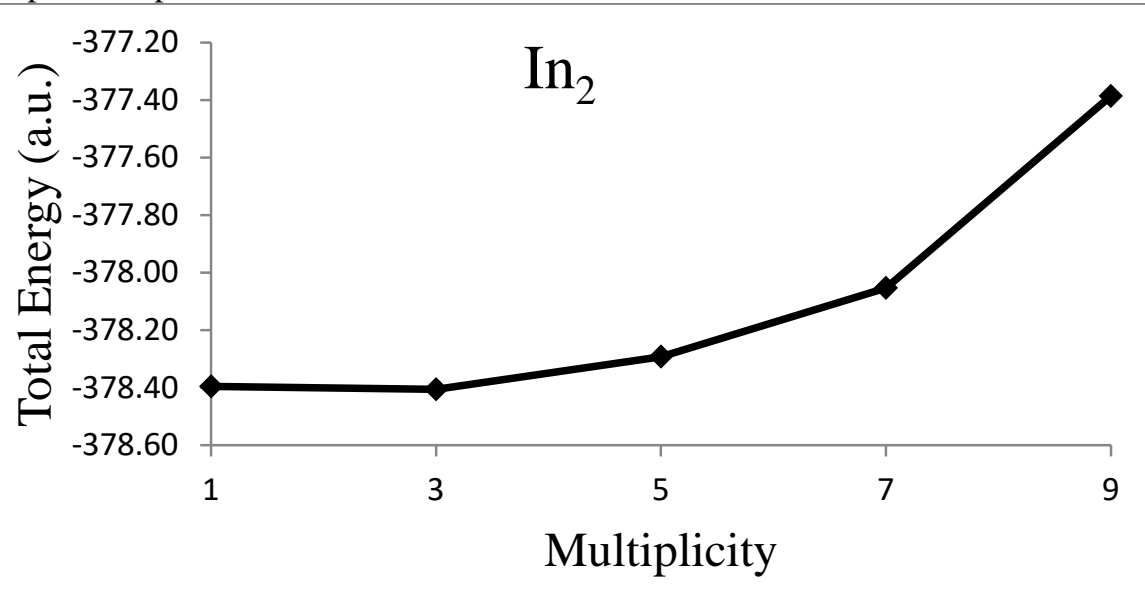

Figure 3. The variation of the total energy versus the spin multiplicity for $\operatorname{In}_{2}$.

$\mathrm{In}_{2}$ homo-nuclear diatom for the most stable structures and its ground state are given in Table 3. In the present study, bond length and vibrational frequency of $\mathrm{In}_{2}$ diatom are calculated to be 3.3846 $\AA$, $96.33 \quad \mathrm{~cm}^{-1}$ in the energetically most favorable ground state and 3.0894 $\AA$, $\quad 106.58 \mathrm{~cm}-1$ in the most stable spin state [multiplicity $=3$ ] by B3LYP/CEP-121G level of theory. The present results especially binding energy agree very well with experimental result in the literature. It is used doublet spin state of In atom which is the most stable state while the calculation of the binding energy for the energetically most favorable ground state of $\operatorname{In}_{2}$. Conformably, for the calculation of the binding energy of $\mathrm{In}_{2}$ in the triplet state it is considered doublet state is the most stable state of In atom. 
Table 3. Spectroscopic constants of $\mathrm{In}_{2}$ in ground state (with minimum multiplicity) and in the most stable state (with minimum total energy). Equilibrium interatomic separation $r_{e}(\AA)$, fundamental frequency $\omega_{\mathrm{e}}\left(\mathrm{cm}^{-1}\right)$, total energy $\mathrm{E}_{\mathrm{T}}$ (a.u.).

\begin{tabular}{|c|c|c|c|c|c|}
\hline $\begin{array}{c}\text { Multiplicity } \\
(2 \mathrm{~S}+1)\end{array}$ & $\mathrm{r}_{\mathrm{e}}$ & $\omega_{\mathrm{e}}$ & $\mathrm{E}_{\mathrm{T}}$ & Method & Reference \\
\hline 1 & 3.3846 & 96.33 & -378.3957 & DFT & This work \\
\hline 3 & 3.0894 & 106.58 & -378.4057 & DFT & This work \\
\hline & 2.20 & 402 & & DFT & {$[62]$} \\
\hline & 2.80 & 111 & & Exp. & {$[63]$} \\
\hline
\end{tabular}

\section{Heteronuclear diatoms}

\section{MnNi Diatom}

For $\mathrm{MnNi}$, the energy of the singlet, triplet, quintet, septet and nonet spin multiplicities are calculated and the octet spin state is found to be as the most stable state as seen from Fig.4.

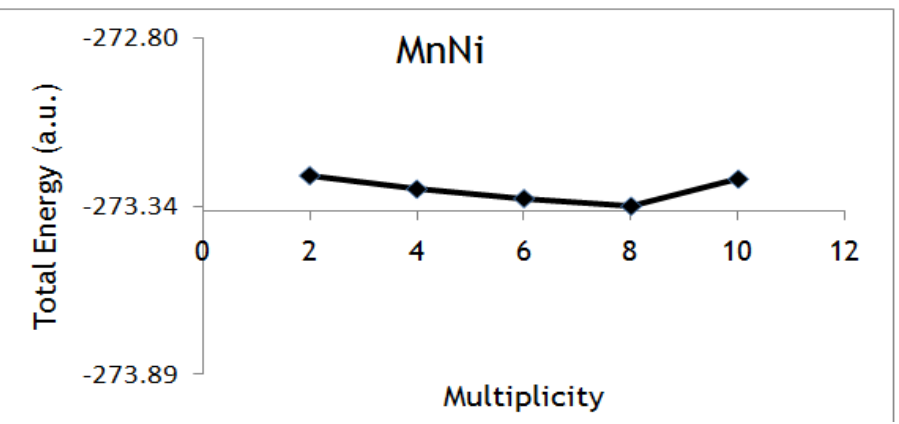

Figure 4. The variation of the total energy versus the spin multiplicity for $\mathrm{MnNi}$.

Binding enery for $\mathrm{MnNi}$ calculated as $2.8249 \mathrm{eV}$ in octet spin state. In the calculation regarding different spin state caused the difference between these two value.
Also, calculated equilibrium interatomic separation and fundemental frequencies both doublet and octet spin states for MnNi dimer are given in Table 4.

Table 4. Spectroscopic constants of heteronuclear diatoms in ground state (with minimum multiplicity) and in the most stable state (with minimum total energy). Binding energy $E_{b}(e V)$, equilibrium interatomic separation $r_{e}$ $(\AA)$, fundamental frequency $\omega_{\mathrm{e}}\left(\mathrm{cm}^{-1}\right)$, total energy $\mathrm{E}_{\mathrm{T}}$ (a.u.).

\begin{tabular}{|c|c|c|c|c|c|c|}
\hline Diatom & $2 \mathrm{~S}+1$ & $\mathrm{r}_{\mathrm{e}}$ & $\omega_{\mathrm{e}}$ & $\mathrm{E}_{\mathrm{T}}$ & Method & Reference \\
\hline $\mathrm{MnNi}$ & 2 & 2.3903 & 212.19 & -273.2429 & DFT & This work \\
\hline $\mathrm{MnNi}$ & 8 & 2.4251 & 214.79 & -273.3439 & DFT & This work \\
\hline $\mathrm{MnIn}$ & 1 & 2.7065 & 179.89 & -292.9247 & DFT & This work \\
\hline MnIn & 5 & 2.5450 & 212.17 & -293.0125 & DFT & This work \\
\hline NiIn & 2 & 2.6500 & 168.55 & -358.6996 & DFT & This work \\
\hline
\end{tabular}

\section{MnIn Diatom}

For MnIn, the energy of the singlet, triplet, quintet, septet and nonet spin multiplicities are calculated and the quintet spin state is found to be as the most stable state as seen from Fig.5.

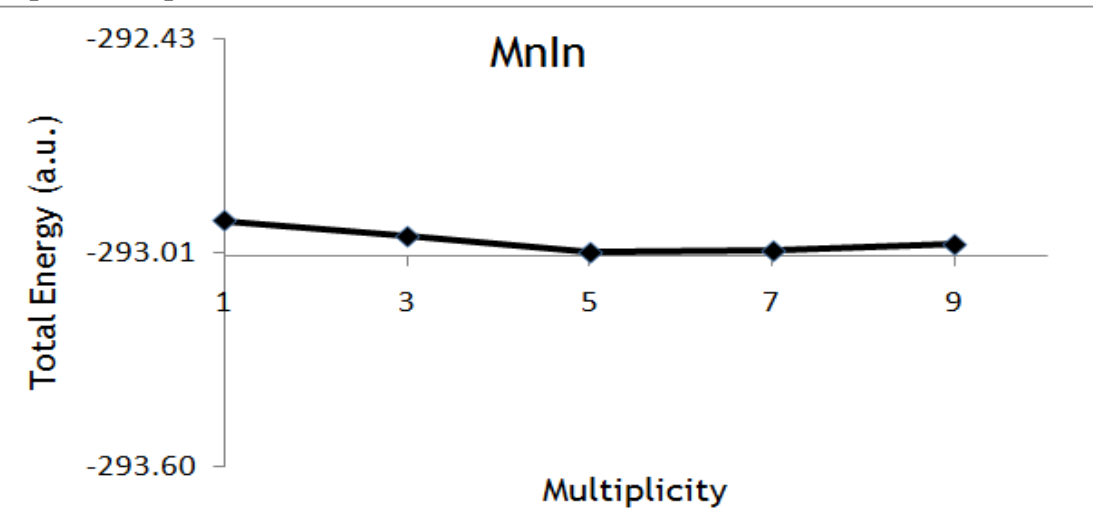

Fig. 5. The variation of the total energy versus the spin multiplicity for MnIn. 
Binding enery for MnIn calculated as $1.1544 \mathrm{eV}$ in quintet spin state. In the calculation regarding different spin state caused the difference between these two value. Also, calculated equilibrium interatomic separation and fundemental frequencies both doublet and octet spin states for MnIn dimer are given in Table 4.

\section{InNi Diatom}

For InNi, the energy of the singlet, triplet, quintet, septet and nonet spin multiplicities are calculated and the doublet spin state is found to be as the most stable state as seen from Figure 6.

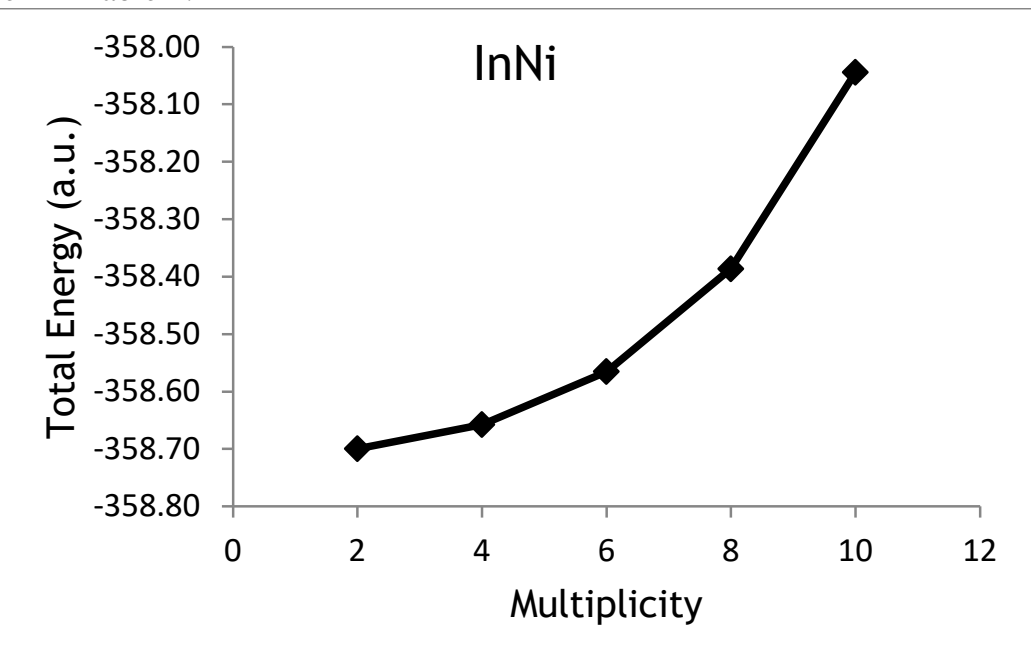

Figure 6. The variation of the total energy versus the spin multiplicity for InNi.

The most stable state and the ground state is equilibrium interatomic separation and fundemental frequencies both doublet and octet spin states for the same so binding enery for $\mathrm{InNi}$ calculated as MnIn diatom are given in Table 4. $1.9172 \mathrm{eV}$ in doublet spin state. Also, calculated

Table 5. The variation of the dipole moment according to the spin multiplicities.

\begin{tabular}{|c|c|c|c|}
\hline Dimer & $\begin{array}{l}\text { Multiplicity } \\
\qquad(2 s+1)\end{array}$ & $\begin{array}{c}\mathrm{E}_{\mathrm{T}} \text { (Total Energy) } \\
\text { (a. u.) }\end{array}$ & $\begin{array}{l}\text { Dipol Moment } \\
\text { (Debye) }\end{array}$ \\
\hline \multirow{5}{*}{ InNi } & 2 & -358.69961115 & 1.7122 \\
\hline & 4 & -358.65761688 & 0.0052 \\
\hline & 6 & -358.56533281 & 0.3042 \\
\hline & 8 & -358.38647785 & 0.5610 \\
\hline & 10 & -358.04435666 & 0.8973 \\
\hline & & & \\
\hline \multirow{5}{*}{ MnIn } & 1 & -292.92474121 & 1.1005 \\
\hline & 3 & -292.96760611 & 0.8127 \\
\hline & 5 & -293.01253643 & 1.1210 \\
\hline & 7 & -293.00707322 & 0.5548 \\
\hline & 9 & -292.99069811 & 0.6397 \\
\hline \multirow{5}{*}{$\mathrm{MnNi}$} & 2 & -273.24293270 & 0.9890 \\
\hline & 4 & -273.28746312 & 1.1276 \\
\hline & 6 & -273.31883006 & 0.8916 \\
\hline & 8 & -273.34396817 & 0.9991 \\
\hline & 10 & -273.25429041 & 0.1481 \\
\hline
\end{tabular}

Table 5 tabulates the total energy and dipole moment values of the diatoms according to the spin multiplicities. For the InNi (at spin state 2) and MnIn (at spin state 5) diatoms the dipole moments are the highest values while the total energies are minimum (stable state). However, for $\mathrm{MnNi}$ diatom the largest dipole moment value does not correspond to the lowest energy value. 


\section{Electronic Properties}

For understanding many molecular properties of a molecule like chemical reactivity, UV-Vis spectra and the stability of the molecule along with optical and electrical properties, analysis of the molecular orbitals gap gives us some informations. Also, the structure properties of the clusters can be examined by investigating highest occupied molecular orbital (HOMO) and lowest unoccupied molecular orbital (LUMO) [64]. The frontier molecular orbitals of the most stable states of the diatoms considered are presented in Fig.7.

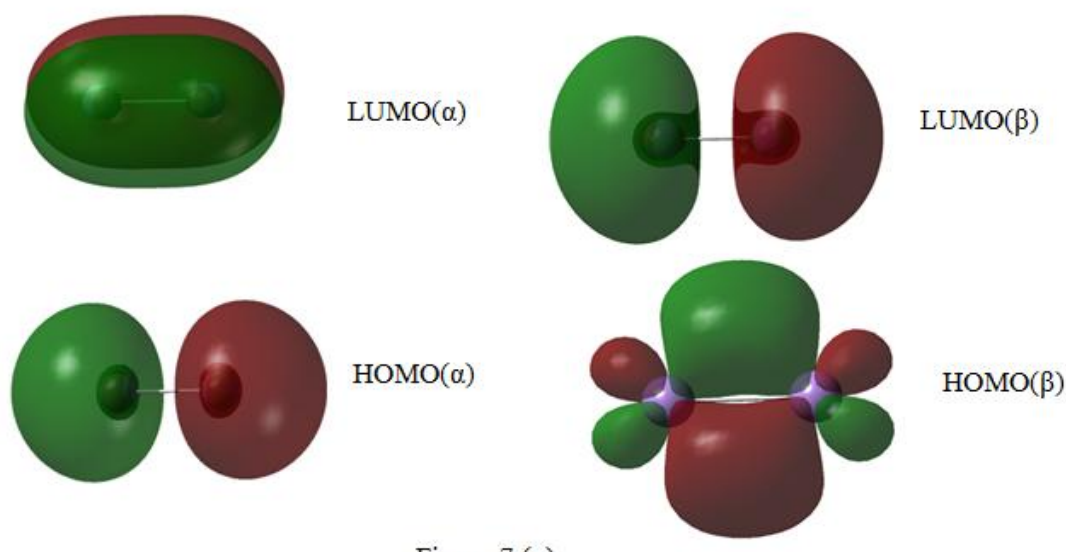

Figure 7 (a)
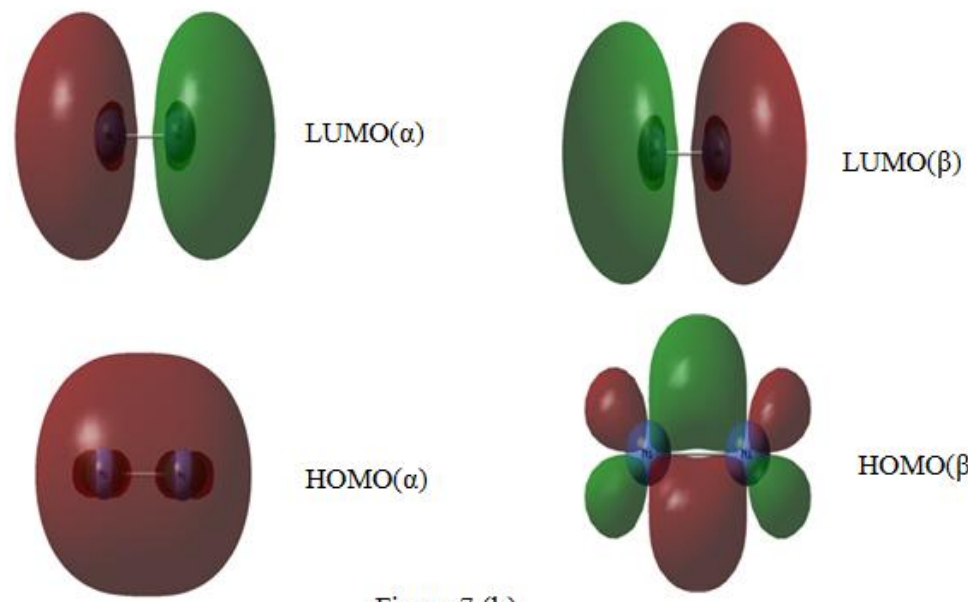

$\operatorname{HOMO}(\alpha)$

Figure 7 (b)

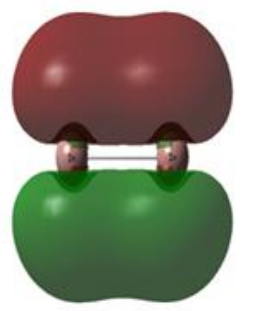

$\operatorname{LUMO}(\alpha)$

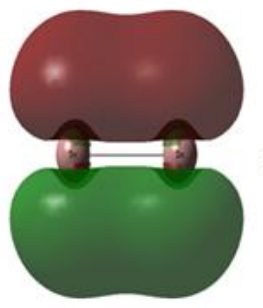

$\operatorname{HOMO}(\alpha)$
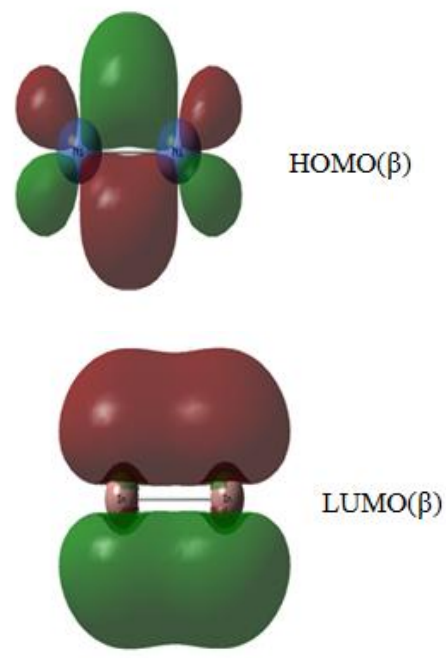

Figure 7 (c)

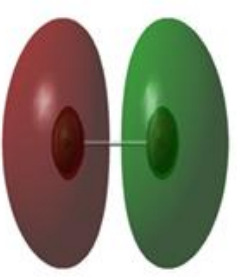

$\operatorname{HOMO}(\beta)$ 

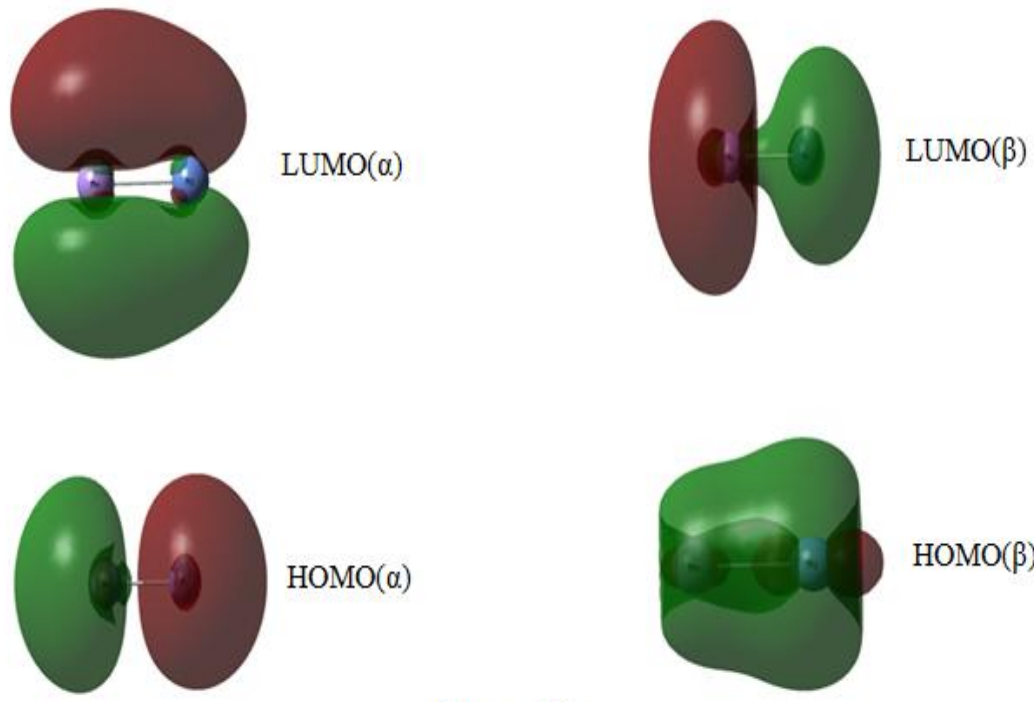

$\operatorname{HOMO}(\beta)$

Figure $7(d)$
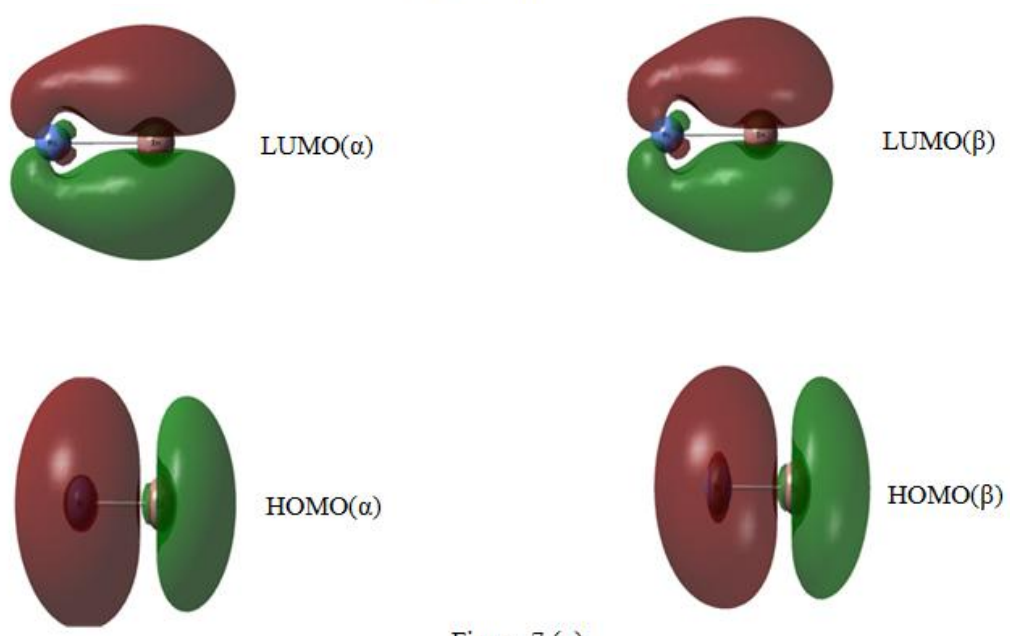

Figure 7 (e)
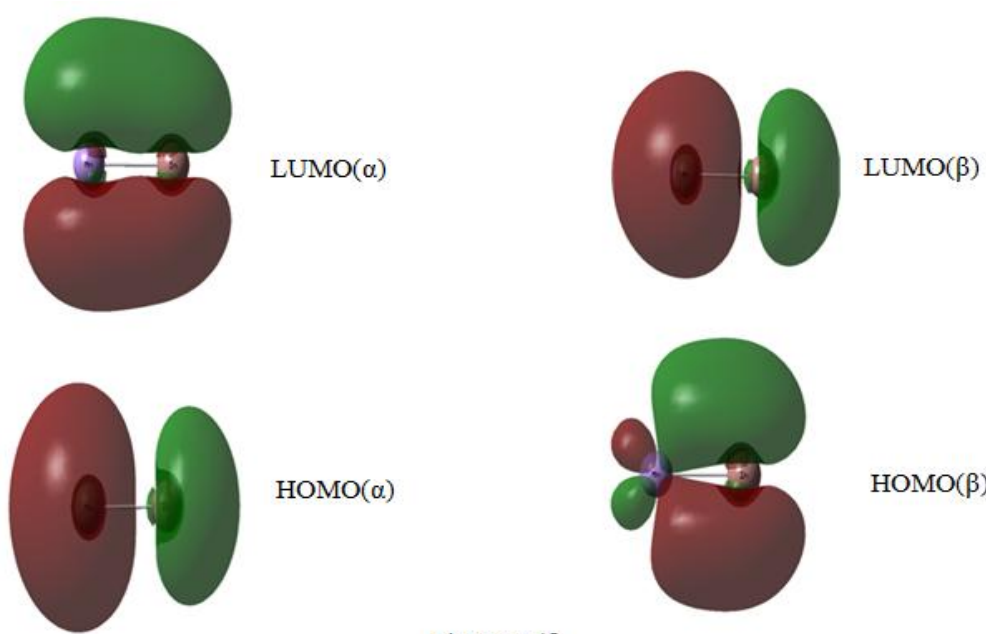

$\operatorname{HOMO}(\alpha)$

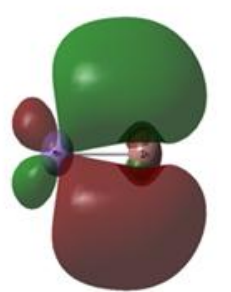

$\operatorname{HOMO}(\beta)$

Figure 7 (f)

Figure 7. Figure 7 (a) $\mathrm{Mn}_{2}$ 11-et, Figure 7 (b) $\mathrm{Ni}_{2}$ triplet, Figure 7 (c) $\mathrm{In}_{2}$ triplet, Figure 7 (d) MnNi octet, Figure (e) NiIn, Figure (f) MnIn quintet; 3D plots of HOMO and LUMO of the Mn-In-Ni diatoms. Table 6 summarizes the binding energy $\left(\mathrm{E}_{\mathrm{b}}\right)$ values calculated from the following equation:

$E_{b}=(E($ diatom $($ lowest spin state $))-E($ atomA $($ lowest spin state $))-E($ atomB $($ lowest spin state $)))$ 
The value of binding energy gives information about the power of chemical bond in clusters since it might help to explain the reactivity of the system [65].

Table 6. Calculated binding energy values for the homonuclear and heteronuclear diatoms.

\begin{tabular}{|c|c|c|c|c|}
\hline Diatom & $\mathrm{E}_{\mathrm{A}}$ (lowest spin state) a.u. & $\mathrm{E}_{\mathrm{B}}$ (lowest spin state) a.u. & $\mathrm{E}_{\mathrm{AB}}$ (lowest spin state) a.u. & $\mathrm{E}_{\mathrm{B}}(\mathrm{eV})$ \\
\hline $\mathrm{Mn}_{2}$ & -103.7906 (Mn-sextet) & -103.7906 (Mn-sextet) & $-207.6899\left(\mathrm{Mn}_{2}\right.$-11-et) & 2.9559 \\
\hline $\mathrm{In}_{2}$ & -189.1796 (In-doublet) & -189.1796 (In-doublet) & $-378.4058\left(\mathrm{In}_{2}\right.$-triplet) & 1.2695 \\
\hline $\mathrm{Ni}_{2}$ & -169.4496 (Ni-triplet) & -169.4496 (Ni-triplet) & $-338.9438\left(\mathrm{Ni}_{2}\right.$-triplet) & 1.2116 \\
\hline $\mathrm{MnIn}$ & -103.7906 (Mn-sextet) & -189.1796 (In-doublet) & -293.0125 (MnIn-quintet) & 1.1544 \\
\hline $\mathrm{InNi}$ & -189.1796 (In-doublet) & -169.4496 (Ni-triplet) & -358.6996 (InNi-doublet) & 1.9172 \\
\hline $\mathrm{MnNi}$ & -103.7906 (Mn-sextet) & -169.4496 (Ni-triplet) & -273.3440 (MnNi-octet) & 2.8249 \\
\hline
\end{tabular}

Table 7 reports calculated values of the frontier orbitals and their gap energies in ground state and the most stable state for homonuclear $\left(\mathrm{Mn}_{2}, \mathrm{Ni}_{2}\right.$, $\left.\mathrm{In}_{2}\right)$ and heteronuclear $(\mathrm{MnNi}, \mathrm{MnIn}, \mathrm{NiIn})$ diatoms. The homonuclear $\left(\mathrm{Mn}_{2}, \mathrm{Ni}_{2}, \mathrm{In}_{2}\right)$ diatoms have much more charge transfer in their structure since their HOMO-LUMO gap values are smaller than the heteronuclear (MnNi, MnIn, NiIn) diatoms.

Table 7. HOMO and LUMO energies (Hartrees), HOMO-LUMO Gap $\left(\mathrm{E}_{\mathrm{g}}\right)$ Energies $(\mathrm{eV})$ for the ground state (with minimum multiplicity) and also for the most stable state (with minimum total energy) of the diatoms.

\begin{tabular}{|c|c|c|c|c|c|c|c|}
\hline Cluster & $2 \mathrm{~S}+1$ & $\mathrm{HOMO}(\alpha)$ & $\mathrm{LUMO}(\alpha)$ & $\mathrm{E}_{\mathrm{g}}(\alpha)$ & $\mathrm{HOMO}(\beta)$ & $\mathrm{LUMO}(\beta)$ & $\mathrm{E}_{\mathrm{g}}(\beta)$ \\
\hline $\mathrm{Mn}_{2}$ & 1 & -0.162 & -0.075 & 2.367 & & & \\
\hline $\mathrm{Mn}_{2}$ & 11 & -0.166 & -0.057 & 0.109 & -0.133 & -0.084 & 0.049 \\
\hline $\mathrm{Ni}_{2}$ & 1 & -0.201 & -0.125 & 2.068 & & & \\
\hline $\mathrm{Ni}_{2}$ & 3 & -0.213 & -0.187 & 0.707 & -0.094 & -0.086 & 2.558 \\
\hline $\mathrm{In}_{2}$ & 1 & -0.108 & -0.071 & 1.007 & & & \\
\hline $\mathrm{In}_{2}$ & 3 & -0.127 & -0.087 & 1.088 & -0.267 & -0.78 & 7.265 \\
\hline $\mathrm{MnNi}$ & 2 & -0.178 & -0.091 & 2.367 & -0.141 & -0.028 & 3.837 \\
\hline $\mathrm{MnNi}$ & 8 & -0.162 & -0.056 & 2.884 & -0.200 & -0.094 & 5.442 \\
\hline $\mathrm{MnIn}$ & 1 & -0.163 & -0.069 & 2.558 & & & \\
\hline $\mathrm{MnIn}$ & 5 & -0.198 & -0.063 & 3.674 & -0.133 & -0.122 & 3.619 \\
\hline $\mathrm{NiIn}$ & 2 & -0.170 & -0.073 & 2.640 & -0.168 & -0.073 & 4.572 \\
\hline
\end{tabular}

Following Koopmans' theorem [66] one can define ionization potential and electron affinity of a species in terms of frontier molecular orbital energies, respectively, as follows: $\mathrm{I}=-\mathrm{E}_{\mathrm{HOMO}}$ and $\mathrm{A}$ $=-\mathrm{E}_{\mathrm{LumO}}$. Here $\mathrm{E}_{\mathrm{HOMO}}$ and $\mathrm{E}_{\mathrm{LumO}}$ represent the highest occupied molecular orbital and the lowest unoccupied molecular orbital energies, respectively. These quantities are commenly used to define some physical and/or chemical quantities [67], such as the global hardness $\eta=(\mathrm{I}-\mathrm{A}) / 2$, the global softness $\mathrm{S}=$ $1 /(2 \eta)$, the electronic chemical potential $\mu=-(\mathrm{I}+\mathrm{A}) / 2=-\chi(\chi$ is electronegativity $)$, and the global electrophilicity index $\omega=\mu^{2} /(2 \eta)$, which measures the affinity of species to attract electrons. Another electronic quantity called HOMO-LUMO gap, which reflects the ability for electrons to jump from the highest occupied to the lowest unoccupied molecular orbital, as well as the ability for the species to participate in the chemical reactions to a certain extent. A large gap value stands for a high chemical stability.

Electronic properties of the homonuclear and heteronuclear diatoms changing by the spin multiplicity are shown in Table 8 . As seen from the Table 8 the softness of the homonuclaer diatoms have the largest values when they are at the minimum multiplicity states, whereas the heteronuclear diatoms have the largest values when they are at minimum energy state. Also electronegativity for the homonuclear diatoms have the lowest values when they are at their minimum multiplicity states.

Table 8. Electronic properties of the homonuclear and heteronuclear diatoms changing by the spin multiplicity (only for $\alpha$-spin case). All units are in $\mathrm{eV}$.

\begin{tabular}{|c|c|c|c|c|c|c|c|c|c|c|c|}
\hline Cluster & Multiplicity & $\mathrm{HOMO}_{\alpha}$ & $\mathrm{LUMO}_{\alpha}$ & $\Delta \mathrm{E}_{\alpha}$ & $\mathrm{I}_{\alpha}$ & $\mathrm{A}_{\alpha}$ & $\chi_{\alpha}$ & $\eta_{\alpha}$ & $\mathrm{S}_{\alpha}$ & $\mu_{\alpha}$ & $\omega_{\alpha}$ \\
\hline \multirow{4}{*}{$\mathrm{Mn}_{2}$} & 1 & -0.16 & -0.07 & 0.09 & 0.16 & 0.07 & 0.12 & 0.04 & 26.67 & -0.12 & 0.1872 \\
\cline { 2 - 13 } & 3 & -5.45 & -2.21 & 3.24 & 5.45 & 2.21 & 3.83 & 1.11 & 0.91 & -3.83 & 6.6324 \\
\cline { 2 - 12 } & 5 & -4.91 & -2.25 & 2.66 & 4.91 & 2.26 & 3.58 & 1.13 & 0.89 & -3.58 & 5.6920 \\
\cline { 2 - 12 } & 7 & -4.93 & -3.92 & 1.01 & 4.93 & 3.92 & 4.43 & 1.96 & 0.51 & -4.43 & 4.9966 \\
\hline
\end{tabular}




\begin{tabular}{|c|c|c|c|c|c|c|c|c|c|c|c|}
\hline & 9 & -0.23 & -0.11 & 0.12 & 0.23 & 0.11 & 0.17 & 0.06 & 17.70 & -0.17 & 0.2664 \\
\hline & 11 & -4.52 & -1.56 & 2.96 & 4.52 & 1.56 & 3.03 & 0.78 & 1.28 & -3.03 & 5.9138 \\
\hline & & & & & & & & & & & \\
\hline \multirow{5}{*}{$\mathrm{Ni}_{2}$} & 1 & -0.20 & -0.12 & 0.08 & 0.20 & 0.12 & 0.16 & 0.06 & 16.00 & -0.16 & 0.2126 \\
\hline & 3 & -0.21 & -0.19 & 0.02 & 0.21 & 0.19 & 0.20 & 0.09 & 10.70 & -0.20 & 0.2139 \\
\hline & 5 & -4.18 & -1.32 & 2.86 & 4.18 & 1.32 & 2.76 & 0.66 & 1.52 & -2.76 & 5.7423 \\
\hline & 7 & -3.37 & -2.19 & 1.18 & 3.37 & 2.19 & 2.78 & 1.10 & 0.91 & -2.78 & 3.5334 \\
\hline & 9 & -4.24 & -2.31 & 1.93 & 4.24 & 2.31 & 3.27 & 1.15 & 0.87 & -3.27 & 4.6419 \\
\hline & & & & & & & & & & & \\
\hline \multirow{5}{*}{$\mathrm{In}_{2}$} & 1 & -0.11 & -0.07 & 0.04 & 0.11 & 0.07 & 0.09 & 0.04 & 28.17 & -0.09 & 0.1128 \\
\hline & 3 & -0.13 & -0.09 & 0.04 & 0.13 & 0.09 & 0.11 & 0.04 & 22.99 & -0.11 & 0.1316 \\
\hline & 5 & -4.26 & -1.22 & 3.04 & 4.26 & 1.22 & 2.74 & 0.61 & 1.64 & -2.74 & 6.1687 \\
\hline & 7 & -3.33 & -2.35 & 0.98 & 3.33 & 2.35 & 2.84 & 1.18 & 0.85 & -2.84 & 3.4362 \\
\hline & 9 & -4.23 & -1.89 & 2.34 & 4.23 & 1.89 & 3.06 & 0.95 & 1.06 & -3.06 & 4.9556 \\
\hline \multirow{5}{*}{$\mathrm{MnNi}$} & 2 & -0.18 & -0.09 & 0.09 & 0.18 & 009 & 013 & 0.05 & 21.98 & -013 & 0.1988 \\
\hline & 4 & $\begin{array}{l}-4.61 \\
\end{array}$ & -2.51 & 2.11 & 4.61 & 2.51 & 3.56 & 1.25 & 0.80 & -3.56 & 5.0562 \\
\hline & 6 & -4.84 & -2.43 & 2.41 & 4.84 & 2.43 & 3.64 & 1.21 & 0.82 & -3.64 & 5.4408 \\
\hline & 8 & -0.16 & -0.06 & 0.11 & 0.16 & 0.06 & 0.11 & 0.03 & 35.71 & -0.11 & 0.2122 \\
\hline & 10 & -3.15 & -2.06 & 1.08 & 3.15 & 2.06 & 2.61 & 1.03 & 0.97 & -2.61 & 3.2912 \\
\hline \multirow{5}{*}{ MnIn } & 1 & -0.16 & -0.07 & 0.09 & 0.16 & 0.07 & 0.12 & 0.04 & 28.99 & -0.12 & 0.1950 \\
\hline & 3 & -4.67 & -2.35 & 2.32 & 4.67 & 2.35 & 3.51 & 1.17 & 0.85 & -3.51 & 5.2413 \\
\hline & 5 & -0.20 & -0.06 & 0.14 & 0.20 & 0.06 & 0.13 & 0.03 & 31.75 & -0.13 & 0.2703 \\
\hline & 7 & -3.37 & -2.00 & 1.37 & 3.37 & 2.00 & 2.68 & 1.00 & 1.00 & -2.68 & 3.6060 \\
\hline & 9 & -3.75 & -2.60 & 1.15 & 3.75 & 2.60 & 3.17 & 1.30 & 0.77 & -3.17 & 3.8752 \\
\hline \multirow{5}{*}{ NiIn } & 2 & -0.17 & -0.07 & 0.10 & 0.17 & 0.07 & 0.12 & 0.04 & 27.40 & -0.12 & 0.2022 \\
\hline & 4 & -3.33 & -2.16 & 1.16 & 3.33 & 2.16 & 2.75 & 1.08 & 0.92 & -2.75 & 3.4844 \\
\hline & 6 & -3.84 & -2.52 & 1.32 & 3.84 & 2.52 & 3.18 & 1.26 & 0.79 & -3.18 & 4.0145 \\
\hline & 8 & -4.274 & -1.40 & 2.87 & 4.27 & 1.40 & 2.83 & 0.70 & 1.43 & -2.83 & 5.7393 \\
\hline & 10 & -3.52 & -2.50 & 1.02 & 3.52 & 2.50 & 3.01 & 1.25 & 0.80 & -3.01 & 3.6189 \\
\hline
\end{tabular}

Table 9. Electronic properties of the homonuclear and heteronuclear diatoms changing by the spin multiplicity (only for $\beta$-spin case). All units are in $\mathrm{eV}$.

\begin{tabular}{|c|c|c|c|c|c|c|c|c|c|c|c|}
\hline Cluster & Multiplicity & $\mathrm{HOMO}_{\beta}$ & $\mathrm{LUMO}_{\beta}$ & $\Delta \mathrm{E}_{\beta}$ & $\mathrm{I}_{\beta}$ & $\mathrm{A}_{\beta}$ & $\chi_{\beta}$ & $\eta_{\beta}$ & $\mathrm{S}_{\beta}$ & $\mu_{\beta}$ & $\omega_{\beta}$ \\
\hline \multirow{4}{*}{$\mathrm{In}_{2}$} & 3 & -7.29 & -2.13 & 5.16 & 7.29 & 2.13 & 4.71 & 2.58 & 0.39 & -4.71 & 4.2905 \\
\hline & 5 & -9.63 & -5.67 & 3.96 & 9.63 & 5.67 & 7.65 & 1.98 & 0.51 & -7.65 & 14.7703 \\
\hline & 7 & -21.15 & -7.80 & 13.35 & 21.15 & 7.80 & 14.47 & 6.68 & 0.15 & -14.47 & 15.6842 \\
\hline & 9 & -22.55 & -21.59 & 0.96 & 22.55 & 21.59 & 22.07 & 0.48 & 2.08 & -22.07 & 505.3350 \\
\hline \multirow{6}{*}{$\mathrm{Mn}_{2}$} & & & & & & & & & & & \\
\hline & 3 & -3.84 & -2.05 & 1.79 & 3.84 & 2.05 & 2.95 & 0.89 & 1.12 & -2.95 & $\begin{array}{l}4.2905 \\
1.7703\end{array}$ \\
\hline & 5 & -3.63 & -1.94 & 1.68 & 3.63 & 1.94 & 2.78 & 0.84 & 1.19 & -2.78 & 14.7703 \\
\hline & 7 & -3.92 & -1.97 & 1.95 & 3.92 & 1.97 & 2.96 & 0.97 & 1.03 & -2.95 & 15.6842 \\
\hline & 9 & -3.84 & -1.77 & 2.06 & 3.84 & 1.77 & 2.80 & 1.03 & 0.97 & -2.80 & 505.3350 \\
\hline & 11 & -3.62 & -2.30 & 1.32 & 3.62 & 2.30 & 2.96 & 0.66 & 1.51 & -2.96 & 4.2905 \\
\hline & & & & & & & & & & & \\
\hline \multirow{4}{*}{$\mathrm{Ni}_{2}$} & 3 & -5.09 & -2.34 & 2.75 & 5.09 & 2.34 & 3.72 & 1.37 & 0.73 & -3.72 & 5.0300 \\
\hline & 5 & -5.60 & -4.78 & 0.82 & 5.60 & 4.78 & 5.19 & 0.41 & 2.45 & -5.19 & 32.9829 \\
\hline & 7 & -7.33 & -5.86 & 1.46 & 7.33 & 5.86 & 6.60 & 0.73 & 1.37 & -6.60 & 29.7524 \\
\hline & 9 & -9.97 & -8.70 & 1.27 & 9.97 & 8.70 & 9.34 & 0.644 & 1.574 & -9.34 & 68.6502 \\
\hline \multirow{4}{*}{ InNi } & 2 & -4.5 & -2.00 & 2.57 & 4.57 & 2.00 & 3.29 & 1.29 & 0.78 & -3.29 & 55 \\
\hline & 4 & -5.91 & -3.55 & 2.36 & 5.91 & 3.55 & 4.73 & 1.18 & 0.85 & -4.73 & 9.5008 \\
\hline & 6 & -9.30 & -5.23 & 4.07 & 9.30 & 5.23 & 7.27 & 2.04 & 0.49 & -7.27 & 12.9732 \\
\hline & 8 & -11.97 & -7.32 & 4.65 & 11.97 & 7.32 & 9.64 & 2.32 & 0.43 & -9.64 & 19.9874 \\
\hline
\end{tabular}



ISSN : 2248-9622, Vol. 7, Issue 7, ( Part -6) July 2017, pp.30-43

\begin{tabular}{|c|c|c|c|c|c|c|c|c|c|c|c|}
\hline & 10 & -18.39 & -11.49 & 6.90 & 18.39 & 11.49 & 14.94 & 3.45 & 0.29 & -14.94 & 32.3400 \\
\hline & & & & & & & & & & & \\
\hline \multirow{5}{*}{$\mathrm{MnNi}$} & 2 & -3.84 & -2.33 & 1.51 & 3.84 & 2.33 & 3.09 & 0.75 & 1.32 & -3.09 & 6.3173 \\
\hline & 4 & -2.62 & -2.22 & 0.40 & 2.62 & 2.22 & 2.42 & 0.20 & 4.98 & -2.42 & 14.6146 \\
\hline & 6 & -4.32 & -2.12 & 2.20 & 4.32 & 2.12 & 3.22 & 1.10 & 0.91 & -3.22 & 4.6957 \\
\hline & 8 & -5.47 & -2.59 & 2.88 & 5.47 & 2.59 & 4.03 & 1.44 & 0.69 & -4.03 & 5.6227 \\
\hline & 10 & -7.45 & -4.33 & 3.12 & 7.45 & 4.33 & 5.89 & 1.56 & 0.64 & -5.89 & 11.1121 \\
\hline & & & & & & & & & & & \\
\hline \multirow{4}{*}{ MnIn } & 3 & -4.40 & -1.83 & 2.57 & 4.40 & 1.83 & 3.12 & 1.29 & 0.78 & -3.12 & 6.3173 \\
\hline & 5 & -3.641 & -3.35 & 0.29 & 3.64 & 3.35 & 3.49 & 0.15 & 6.81 & -3.49 & 14.6146 \\
\hline & 7 & -3.88 & -3.27 & 0.61 & 3.88 & 3.27 & 3.58 & 0.30 & 3.29 & -3.58 & 4.6957 \\
\hline & 9 & -8.92 & -3.88 & 5.04 & 8.92 & 3.88 & 6.40 & 2.52 & 0.40 & -6.40 & 5.6227 \\
\hline
\end{tabular}

\section{CONCLUSION}

For the different spin multiplicities the structures of Mn-In-Ni diatoms have been calculated at B3LYP/CEP-121G level. According to the results, the equilibrium structures of the Mn-In-Ni diatoms are in different multiplicities. The localization of the charge density of the diatoms are in central region, this indicates that bonding character of the diatoms are semimetalic.

\section{ACKNOWLEDGEMENT}

This study was supported by Pamukkale University [Grant no: 2012BSP004].

\section{REFERENCES}

[1] Halicioglu, T.; Bauschlicher, C. W. Physics of Microclusters. Reports Prog. Phys. 1988, 51 (6), 883-921 DOI: 10.1088/00344885/51/6/003.

[2] Pound, G. M.; Medalist, R. F. M. Perspectives on Nucleation.

[3] Hagena, O. F. Atoms, Molecules and Clusters Condensation in Free Jets: Comparison of Rare Gases and Metals. Mol. Clust. 1987, 4, 291-299.

[4] Pettersson, L. G. M.; Bauschlicher, C. W.; Halicioglu, T. Small Al clusters. II. Structure and binding in Aln $(\mathrm{n}=2-6,13) . J$. Chem. Phys. 1987, 87 (4), 2205.

[5] Feuston, B. P.; Kalia, R. K.; Vashishta, P. Fragmentation of silicon microclusters: A molecular-dynamics study. Phys. Rev. B 1987, 35 (12), 6222-6239.

[6] Blaisten-Barojas, E.; Levesque, D. Molecular-dynamics simulation of silicon clusters. Phys. Rev. B 1986, 34 (6), 39103916.

[7] De Heer, W. A. The physics of simple metal clusters: Experimental aspects and simple models. Rev. Mod. Phys. 1993, 65 (3), 611676.

[8] Hameed, S. A. Ab-Initio Calculations of the Dissociation Energy and Periodic Properties of the Heavy P-block Dimers. JKAU Sci 2009, 21 (2), 227-240.
[9] Terasaki, A.; Minemoto, S.; Kondow, T. Energetics of the manganese trimer and tetramer ions. J. Chem. Phys. 2002, 117 (16), 7520

[10] Desmarais, N.; Reuse, F. A.; Khanna, S. N. Magnetic coupling in neutral and charged $\mathrm{Cr}_{2}, \mathrm{Mn}_{2}$, and CrMn dimers. J. Chem. Phys. 2000, 112 (13), 5576.

[11] Kataoka, T.; Sakamoto, Y.; Yamazaki, Y.; Singh, V. R.; Fujimori, A.; Takeda, Y.; Ohkochi, T.; Fujimori, S.-I.; Okane, T.; Saitoh, Y.; et al. Electronic configuration of $\mathrm{Mn}$ ions in the $\pi$-d molecular ferromagnet $\beta$ Mn phthalocyanine studied by soft X-ray magnetic circular dichroism. Solid State Commun. 2012, 152, 806-809.

[12] Tono, K.; Terasaki, A.; Ohta, T.; Kondow, $\mathrm{T}$. Weak metal-metal bonding in small manganese cluster ions, $\mathrm{Mn}_{\mathrm{N}}{ }^{+}(\mathrm{N} \leq 7) . J$. Chem. Phys. 2005, 123 (17), 174314.

[13] Longo, R. C.; Rey, C.; Gallego, L. J. Structure and melting of small Ni clusters on Ni surfaces. Surf. Sci. 1999, 424, 311-321.

[14] Sakamoto, T.; Tachikawa, H.; Azumi, K. DFT study of 2-butyne-1,4-diol adsorption on $\mathrm{Ni}\left(\begin{array}{lll}1 & 1 & 1\end{array}\right)$ or $\mathrm{Ni}\left(\begin{array}{lll}1 & 0 & 0\end{array}\right)$ clusters. Appl. Surf. Sci. 2012, 258 (18), 6785-6792.

[15] Shewale, V.; Deshpande, M. Structural, electronic, and magnetic properties of

NinM clusters (M=Hf, Ta, W) with $\mathrm{n}=1-12$. Comput. Theor. Chem. 2012, 984, 128136.

[16] Chakrabarti, A.; Barman, S. R. Theoretical prediction of shape memory behavior and ferrimagnetism in $\mathrm{Mn}$ [sub 2]NiIn. Appl. Phys. Lett. 2009, 94 (16), 161908.

[17] Hernando, B.; Sánchez Llamazares, J. L.; Prida, V. M.; Baldomir, D.; Serantes, D.; Ilyn, M.; González, J. Magnetocaloric effect in preferentially textured $\mathrm{Mn}_{50} \mathrm{Ni}_{40} \mathrm{In}_{10}$ melt spun ribbons. Appl. Phys. Lett. 2009, 94 (22), 222502.

[18] Bai, J.; Xu, N.; Raulot, J.-M.; Zhang, Y. D.; Esling, C.; Zhao, X.; Zuo, L. First-principles investigations of crystallographic, magnetic, 
and electronic structures in $\mathrm{Ni}_{2} \mathrm{XIn}(\mathrm{X}=\mathrm{Mn}$, Fe, and Co). J. Appl. Phys. 2012, 112 (11), 114901.

[19] Tan, C. L.; Huang, Y. W.; Tian, X. H.; Jiang, J. X.; Cai, W. Origin of magnetic properties and martensitic transformation of Ni-Mn-In magnetic shape memory alloys. Appl. Phys. Lett. 2012, 100 (13), 132402.

[20] Liu, Z. H.; Li, G. T.; Wu, Z. G.; Ma, X. Q.; Liu, Y.; Wu, G. H. Tailoring martensitic transformation and martensite structure of NiMnIn alloy by Ga doping In. J. Alloys Compd. 2012, 535, 120-123.

[21] Hernando, B.; Llamazares, J. L. S.; Santos, J. D.; Sánchez, M. L.; Escoda, L.; Suñol, J. J.; Varga, R.; García, C.; González, J. Grain oriented NiMnSn and NiMnIn Heusler alloys ribbons produced by melt spinning: Martensitic transformation and magnetic properties. J. Magn. Magn. Mater. 2009, 321 (7), 763-768.

[22] Caneschi, A.; Gatteschi, D.; Sessoli, R.; Schweizer, J. Magnetization density in a Mn high-spin ( $\mathrm{S}=12)$ magnetic cluster. Phys. $B$ Condens. Matter 1997, 241, 600-602.

[23] Medel, V.; Reveles, J. U.; Khanna, S. N. Magnetism of electrons in atoms and superatoms. J. Appl. Phys. 2012, 112 (6), 64313.

[24] Buchachenko, A. A. Ab initio interaction potential of the spin-polarized manganese dimer. Chem. Phys. Lett. 2008, 459 (1), 7376.

[25] López-Urías, F.; Díaz-Ortiz, A. Magnetism and the electronic correlations in $\mathrm{Mn}$ clusters. J. Alloys Compd. 2004, 369 (1), 117-120.

[26] Shalabi, A. S.; Abdel Aal, S.; Abdel Halim, W. S.; Abdullah, N. Spin quenching of Mn in complexes and $\mathrm{CO}$ binding with $\mathrm{Mn}$ deposited on $\mathrm{MgO}$ and $\mathrm{CaO}$ supports: DFT calculations. Int. J. Quantum Chem. 2012, 112 (15), 2743-2751.

[27] Wang, B.; Chen, Z. Unusual magnetic properties of mixed-valence system: Multiconfigurational method theoretical study on $\mathrm{Mn}_{2}{ }^{+}$cation. J. Chem. Phys. 2005, 123 (13), 134306.

[28] Terasaki, A.; Briere, T. M.; Kulawik, M.; Minemoto, S.; Tono, K.; Matsushita, A.; Kondow, T. Ferromagnetic spin coupling in the manganese trimer ion evidenced by photodissociation spectroscopy. J. Chem. Phys. 2003, 118 (5), 2180.

[29] Tono, K.; Terasaki, A.; Ohta, T.; Kondow, T. Electronic structure of $\mathrm{Mn}_{2} \mathrm{O}^{-}$: ferromagnetic spin coupling stabilized by oxidation; J. Chem. Phys. 2004, Vol. 388.
[30] Heo, Y.-U.; Lee, H.-C. The Twin and Twin System in FCT $\mathrm{L}_{0} \theta-\mathrm{MnNi}$ Phase in an Equiatomic $\mathrm{Mn}-\mathrm{Ni}$ Alloy. Materials Transactions 2007, 48 (10), 2546.

[31] Paul, S.; Misra, A. On magnetic nature of Mn clusters. J. Mol. Struct. THEOCHEM 2009, 907 (1-3), 35-40.

[32] Averback, R. S.; Nelson, D. L.; Bernholc, J. Clusters and Cluster Assembled Materials, Proc. Mater. Res. Soc., 1991.

[33] Gao, C. L.; Ernst, A.; Winkelmann, A.; Henk, J.; Wulfhekel, W.; Bruno, P.; Kirschner, J. Noncollinear Surface Spin Density by Surface Reconstruction in the Alloy NiMn. Phys. Rev. Lett. 2008, 100 (23), 237203.

[34] Kohn, W.; Sham, L. J. Self-Consistent Equations Including Exchange and Correlation Effects. Phys. Rev. 1965, 140 (4A), A1133-A1138.

[35] R.G. Parr, W. Yang, Density Functional Theory of Atoms and Molecules; Oxford University Press, 1989.

[36] Stevens, W. J.; Basch, H.; Krauss, M. Compact effective potentials and efficient shared-exponent basis sets for the first- and second-row atoms. J. Chem. Phys. 1984, 81 (12), 6026.

[37] Cundari, T. R.; Stevens, W. J. Effective core potential methods for the lanthanides. $J$. Chem. Phys. 1993, 98 (7), 5555.

[38] Frisch, M. J.; Trucks, G. W.; Schlegel, H. B.; Scuseria, G. E.; Robb, M. A.; Cheeseman, J. R.; Scalmani, G.; Barone, V.; Mennucci, B.; Petersson, G. A.; Nakatsuji, H.; Caricato, M.; Li, X.; Hratchian, H. P.; Izmaylov, A. F.; Bloino, J.; Zheng, G.; Sonnenberg, J. L.; Hada, M.; Ehara, M.; Toyota, K.; Fukuda, R.; Hasegawa, J.; Ishida, M.; Nakajima, T.; Honda, Y.; Kitao, O.; Nakai, H.; Vreven, T.; Montgomery, J. A., Jr.; Peralta, J. E.; Ogliaro, F.; Bearpark, M.; Heyd, J. J.; Brothers, E.; Kudin, K. N.; Staroverov, V. N.; Kobayashi, R.; Normand, J.; Raghavachari, K.; Rendell, A.; Burant, J. C.; Iyengar, S. S.; Tomasi, J.; Cossi, M.; Rega, N.; Millam, J. M.; Klene, M.; Knox, J. E.; Cross, J. B.; Bakken, V.; Adamo, C.; Jaramillo, J.; Gomperts, R.; Stratmann, R. E.; Yazyev, O.; Austin, A. J.; Cammi, R.; Pomelli, C.; Ochterski, J. W.; Martin, R. L.; Morokuma, K.; Zakrzewski, V. G.; Voth, G. A.; Salvador, P.; Dannenberg, J. J.; Dapprich, S.; Daniels, A. D.; Farkas, Ö.; Foresman, J. B.; Ortiz, J. V.; Cioslowski, J.; Fox, D. J.; Gaussian 09, Revision C.01, Gaussian, Inc., Wallingford CT, 2009. 
[39] Dennington, R. T.; Keith, J. M. GaussView, Version 5. Semichem Inc.: Shawnee Mission, KS 2009.

[40] Stevens, W. J.; Krauss, M.; Basch, H.; Jasien, P. G. Relativistic compact effective potentials and efficient, shared-exponent basis sets for the third-, fourth-, and fifthrow atoms. Can. J. Chem. 1992, 70 (2), 612-630.

[41] Michelini, M. C.; Pis Diez, R.; Jubert, A. H. Density functional study of the ionization potentials and electron affinities of small Nin clusters with $\mathrm{n}=2-6$ and 8. Comput. Mater. Sci. 2004, 31 (3), 292-298.

[42] Karayel, A. 1,2,4-Triazol Benzimidazol Türevlerinin Kristal Yapllarl ve YaptAktivite Illişkilerinin $X$ - Işıılarıla ve Kuantum Mekaniksel Yöntemlerle Incelenmesi; Hacettepe Üniversitesi Fen Bilimleri Enstitüsü, 2010.

[43] Woodward, L. A. Introduction to the Theory and Molecular Vibration Spectroscopy; Oxford University Press, 1972.

[44] Chang, R. Basic Principles of Spectroscopy, Mc Graw Hill, 1971.

[45] ZHOU, J.; LI, W.; ZHU, J. Particle swarm optimization computer simulation of Ni clusters. Trans. Nonferrous Met. Soc. China 2008, 18 (2), 410-415.

[46] Nayak, S. .; Jena, P. Anomalous magnetism in small Mn clusters. Chem. Phys.

Lett. 1998, 289 (5), 473-479.

[47] Shim, I.; Dahl, J. P.; Johansen, H. Ab initio Hartree-Fock and configurationinteraction treatment of the interaction between two nickel atoms. Int. J. Quantum Chem. 1979, 15 (3), 311-331.

[48] Castro, M.; Jamorski, C.; Salahub, D. R. Structure, bonding, and magnetism of small Fen, Con, and Nin clusters, $\mathrm{n} \leq 5$. Chem. Phys. Lett. 1997, 271 (1), 133142.

[49] Wolf, A.; Schmidtke, H.-H. Nonempirical calculations on diatomic transition metals. II.RHF investigation of lowest closed-shell states of homonuclear $3 \mathrm{~d}$ transition-metal dimers. Int. J. Quantum Chem. 1980, 18 (5), 1187-1205.

[50] Reuse, F. A.; Khanna, S. N. Geometry, electronic structure, and magnetism of small Nin ( $\mathrm{n}=2-6,8,13)$ clusters. Chem. Phys. Lett. 1995, 234 (1), 77-81.

[51] Shaik, S.; Epiotis, N. D. Qualitative potential energy surfaces. 3. Stereoselection rules for spin inversion in triplet photochemical reactions. J. Am. Chem. Soc. 1978, 100 (1), 18-29.
[52] Harris, J.; Jones, R. O. Density functional theory and molecular bonding. III. Iron-series dimers. J. Chem. Phys. 1979, 70 (2), 830 .

[53] Basch, H.; Newton, M. D.; Moskowitz, J. W. The electronic structure of small nickel atom clusters. J. Chem. Phys. 1980, 73 (9), 4492.

[54] Yamamoto, S.; Tatewaki, H.; Moriyama, H.; Nakano, H. A study of the ground state of manganese dimer using quasidegenerate perturbation theory. $J$. Chem. Phys. 2006, 124 (12), 124302.

[55] Jellinek, J.; Acioli, P. H. Magnesium Clusters: Structural and Electronic Properties and the Size-Induced Nonmetalto-Metal Transition $\uparrow$. J. Phys. Chem. A 2002, 106, 10919.

[56] Shi-Ying, Y.; Guo-Liang, X. Spin polarization effect for Mn 2 molecule. Phys. Soc 2007, 1616 (303), 686-1009.

[57] Angeli, C.; Cavallini, A.; Cimiraglia, R. An $\mathrm{ab}$ initio multireference perturbation theory study on the manganese dimer. J. Chem. Phys. 2008, 128 (24), 244317.

[58] Kirkwood, A. D.; Bier, K. D.; Thompson, J. K.; Haslett, T. L.; Huber, A. S.;

Moskovits, M. Ultraviolet-visible and Raman spectroscopy of diatomic Manganese isolated in rare-gas matrixes. $J$. Phys. Chem. 1991, 95 (7), 2644-2652.

[59] Nayak, S. .; Jena, P. Anomalous magnetism in small Mn clusters. Chem. Phys. Lett. 1998, 289 (5), 473-479.

[60] Camacho, C.; Witek, H. A.; Yamamoto, S. Intruder states in multireference perturbation theory: The ground state of manganese dimer. J. Comput. Chem. 2009, 30 (3), 468478.

[61] Kabir, M.; Mookerjee, A.; Kanhere, D. G. Structure, electronic properties, and magnetic transition in manganese clusters. Phys. Rev. B 2006, 73 (22), 224439.

[62] Erkoç, Ş.; Katircioğlu, Ş.; Yilmaz, T. Structural and electronic properties of InmSen microclusters: density functional theory calculations. J. Mol. Struct. THEOCHEM 2001, 542 (1), 101-105.

[63] Froben, F. W.; Schulze, W.; Kloss, U. Raman spectra of matrix-isolated group IIIA dimers: Ga2, In2, T12. Chem. Phys. Lett. 1983, 99 (5), 500-502.

[64] Diwaker. Quantum mechanical and spectroscopic (FT-IR, 13C, 1H NMR and UV) investigations of 2-(5-(4Chlorophenyl)-3-(pyridin-2-yl)-4,5dihydropyrazol-1-yl)benzo[d]thiazole by DFT method. Spectrochim. Acta - Part 
A Mol. Biomol. Spectrosc. 2014, 128, 819829.

[65] Oymak, H.; Erkoç, Ş. Structural and electronic properties of $\mathrm{Al}_{\mathrm{k}} \mathrm{Ti}_{\mathrm{l}} \mathrm{Ni}_{\mathrm{m}}$

microclusters: Density Functional Theory. Phys. Rev. A 2002, 66 (3), 33202.

[66] Koopmans, T. Ordering of wave functions and eigenenergies to the individual electrons of an atom. Physica 1934, 1 (1-6), 104-113.

[67] Zaater, S.; Bouchoucha, A.; Djebbar, S.; Brahimi, M. Structure, vibrational analysis, electronic properties and chemical reactivity of two benzoxazole derivatives: Functional density theory study. J. Mol. Struct. 2016, doi: 10.1016/j.molstruc.2016.06.047. (2017): 30-43. 